Session 1153

\title{
Impact of Vertically Integrated Team Design Projects on First Year Engineering Students
}

\author{
Helen K. Qammar ${ }^{1}$, H. Michael Cheung ${ }^{1}$, Edward A. Evans ${ }^{1}$, \\ Sandra Prettyman Spickard ${ }^{2}$, Francis S. Broadway ${ }^{3}$, Rex D. Ramsier ${ }^{4}$ \\ Department of Chemical Engineering ${ }^{1} /$ \\ Educational Foundations and Leadership ${ }^{2} /$ \\ Department of Curricular and Instructional Studies ${ }^{3}$ \% \\ Departments of Physics, Chemistry, and Chemical Engineering ${ }^{4}$ \\ The University of Akron \\ Akron, Ohio 44325
}

\section{Introduction}

In this paper we present a novel freshman design experience and the resulting enhancement of the first year experience. For the last five years, the Department of Chemical Engineering at The University of Akron has implemented a Vertically Integrated Team Design Project (VITDP) involving our entire undergraduate student population. VITDP is an engineering design curricular and instructional pilot project for the National Science Foundation-funded Department Level Curriculum Reform (DLCR) at The University of Akron. Teams consisting of freshman through seniors come together with an industrial or faculty mentor to solve an open-ended design problem over a five-week period during the Fall semester. Teams are typically asked to decide whether a proposed engineering project should move into the detailed design phase based on economic, environmental, or safety considerations. Examples of previous projects include the design of a methyl methacrylate process, design modifications to enhance the safety of a polymerization process, and process design for chicken pox vaccine production. For freshman in particular, we seek to introduce them to the field of chemical engineering, prepare them for the breadth of applications needing ChE skills, excite them about continuing in ChE, and build their confidence. These objectives for a freshman course have recently been emphasized in national workshops on curriculum reform ${ }^{1-2}$.

To help freshmen meet the learning objective, each project is specifically designed to require positive interdependency between the team members thus creating an instructional framework where students learn through teaming rather than group work. An obvious question when using a multi-level student team is whether upper-level students will accept inexperienced freshman as effective partners. In addition, freshman may feel overwhelmed by the terminology, design tasks, and feelings of inadequacy leading to negative learning outcomes when placed in such unknown territory. In this paper we describe the developmental stages of our freshman as well as the need and mechanism for imparting value to the freshmen so that teams cannot succeed without involving them. Instruments used in this study include an engineering attitude survey, pre- and post-tests of project relevant content knowledge, reflective journal and end of

"Proceedings of the 2004 American Society for Engineering Education Annual Conference \& Exposition Copyright (C) 2004, American Society for Engineering Education” 
project/course evaluations. The preliminary results indicate that, as a result of participating on a VITDP, first year students greatly enhance their knowledge content and have a significant appreciation for the discipline of chemical engineering. In addition, post-project surveys of the freshman students indicate an overwhelmingly positive attitude toward engineering when the project is designed to encourage good teaming behaviors. We present the lessons learned about implementing a successful first year engineering experience based on multi-level, vertically integrated projects.

\section{Structure for the VITDP}

VITDP is a vertically integrated design experience has been incorporated into four required chemical engineering courses - Tools for Chemical Engineering, Material \& Energy Balances, Mass Transfer, and Process Design I. For the last five years, the Department of Chemical Engineering at The University of Akron has implemented VITDP for the entire undergraduate chemical engineering student population. Rather than segmenting the acquisition of engineering skills via projects in each of the four courses, a common design project is assigned during a five to seven week period in the Fall semester. Our reasoning is that if each course was to include a student-centered design project that varies by complexity and difficulty, why not have a single, realistic project and distribute the students by ability (i.e. class level)? In part due to the strong suggestion of our students who wanted to minimize freeloading of non-motivated team members, VITDP is now a required co-listed, single credit course in each year of the BS program.

Our chemical engineering department is moderate in size with 10 faculty and approximately 160 undergraduate and 40 full-time graduate students. The courses associated with VITDP are only offered during the Fall semester and therefore the team project has been offered only in the Fall. Almost $90 \%$ of our students are involved with alternating coop education semesters that causes a gap in both maturity and experience between juniors and seniors. Seniors will have completed 3 semesters of work experience while juniors will not have started their coop work experiences. A typical distribution of students by level is 32 seniors, 32 juniors, 38 sophomores, and 50 freshmen. Last Fall, we assigned non-engineers, specifically K-12 teachers or teacher candidates to half of the teams. During the Fall of 2003, we had 16 teams for a total of 137 chemical engineering majors, six K-12 educators, 4 engineering faculty mentors and 12 industrial team mentors.

Purposely-constructed teams consisting of all chemical engineering freshmen through seniors come together to work on an open-ended design problem. Three faculty serve as project instructors and there are typically $13-16$ teams with 8-11 students on a team. In Fall 2003 the project was an opportunity to introduce inherent process safety design into the curriculum. A common one-hour recitation time is scheduled each week to ensure that all can attend meetings and to allow pre-project instruction on effective teams and some technically relevant information. During the project period, each team is required to hold five formal one-hour meetings with either an industrial or faculty mentor who provides feedback on the team's progress and teamwork dynamics. Each meeting must have a leader, scribe and facilitator where these roles rotate among members. The mentor may impart some technical advice but their role is primarily as an observer of effective interaction and judge of how well team members are participating during the meeting. Mentors provide immediate feedback to the team at the end of each meeting. Each week, the team submits meeting minutes and an updated project work plan to the project instructors. Students are asked to submit individual work logs describing their weekly activities

"Proceedings of the 2004 American Society for Engineering Education Annual Conference \& Exposition Copyright (C) 2004, American Society for Engineering Education" 
as well as reflective journals. The project instructors grade a final design report and a 15-20 minute oral presentation.

The Tools for Chemical Engineering course plays a larger role than the other courses in teaching some skills and providing information the teams need for project success. Since the Tools freshman may be overwhelmed by the terminology, design tasks, and feelings of inadequacy, we purposely 'plant' information with the freshman. For example, one of their lab assignments prior to the start of VITDP is to search the Internet for patents or project specific web pages they will use in the project. Another lab assignment may ask them to prepare a complete cash flow analysis in Excel. Lectures on teamwork and oral presentation skills emphasize what they can do as freshman and how they can prevent being relegated to a non-participatory role. In-class discussions may revolve around more complete explanations of the problem statement and what the VITDP instructors are looking for in the deliverables. Our experience with VITDP reinforces the idea that knowledge is power and both freshman and sophomores must gain power by their contributions. Team mentors are counseled to encourage freshman to bring important information to team meetings and ask questions during the meeting. All students are counseled that tasks and workload must be fairly distributed although this is perhaps the most difficult aspect of VITDP. The project statement does not specifically assign tasks to each level but requires the team to discuss strengths of each individual and develop a well-planned work plan based on this information. The special considerations given to the freshman are an attempt to impart value so teams cannot succeed without listening to their freshman, a form of positive interdependency ${ }^{3}$.

\section{Pedagogy for the VITDP}

With the project structure in mind, we turn to the literature to evaluate the efficacy of our multilevel design team strategy. For freshman in particular, it has been reported that the level of student integration into the college environment affects their ability to persist in the pursuit of a degree $^{4}$. The multi-level experience is an attempt to create situated learning, a primarily social form of learning ${ }^{5}$. Freshman and lower skilled students share information gathered from their efforts on less technical tasks and so their role is more in peripheral participation versus a leadership role. The upper-level students should gain a deeper understanding of the subject material through their attempts to explain the material to the lower-level students. Case studies have shown that this is a legitimate form of learning and it's effectiveness stems from the circulation of knowledge within the team ${ }^{5}$. If successful, this cooperative learning environment quickly generates positive interdependence since each team member needs to learn from the others for both individual and team success.

Each individual will construct new knowledge and understanding based on what he or she already knows and believe 6 . In other words, "the learner pulls from previous experiences, applies this knowledge to new experiences ... juxtaposes old and new experiences, and then constructs or reconstructs a personal understanding ${ }^{7}$. Radical constructivism, as a way of thinking about knowing, assumes "that knowledge, no matter how it is defined, is in the head of persons, and that the thinking subject has no alternative but to construct what he or she knows on the basis of his or her own experience ${ }^{8}$. On the other hand, "social constructivism emerges out of radical constructivism and is concerned with the contributions of social interactions to the construction of self", In other words, "mental activity is the result of social learning, of the

"Proceedings of the 2004 American Society for Engineering Education Annual Conference \& Exposition Copyright (C) 2004, American Society for Engineering Education" 
internalization of social signs, and of the internalization of culture and of social interactions" ${ }^{\text {. }}$ Thus, epistemologically, knowledge and understanding are personal but socially constructed by the learner.

As students progress through the program they will have repeated practice at developing the socalled career skills of teamwork and communication in addition to enhancing their engineering content knowledge. According to Reynold's ${ }^{11}$ model of developing competency, consistent and reliable performance of a skill occurs after a number of attempts since competency rises just after an attempt but wanes between attempts or experiences. According to Reynolds, students will master skills only after repeated exposure to projects that include these elements. Others have reported this as well ${ }^{12}$. An important distinction between VITDP and more typical in-class projects is the exposure to all elements of design and teamwork including those beyond their immediate competency. Students see the overall, 'big-picture' by participating in the project each year, but they will comprehend more and more aspects with repeated exposure. Constructivism suggests that students will use their memories from prior projects (both positive and negative experiences) and their social interactions with other team members to construct knowledge while simultaneously applying new knowledge gained from increasingly higher-level engineering classes. In essence, VITDP combines Reynold's model with constructivist theory as the mechanism for learning in a cooperative team structure.

\section{Design of the Project Statement}

The challenges in creating the VITDP problem statement so that students learn important engineering and other professional skills are in:

1. creating a set of deliverables that force the teams to stay on track,

2. providing tasks to which the less experienced members of the team can reasonably contribute,

3. crafting a problem which allows students to emphasize the process of using a team format to meet the project goals,

4. allowing each level of student the opportunity to learn something they perceive as valuable, and

5. accomplishing all of the above while keeping the time required manageable for the students.

The specific topic for the project has turned out to be less important than one might suppose provided it meets the above criteria.

The problem statement includes a spectrum of design tasks that require the teams to find and interpret a range of information about the subject area in addition to performing traditional chemical engineering design tasks. The categories that apply most often include: technology reviews (especially utilizing the patent literature), market forecasts, price analysis, safety analysis, and a general analysis of HSE (health, safety, and environment) implications of the product or process under consideration. It is also important to have some of these 'softer' deliverables due throughout the project period to keep the underclassmen engaged while the engineering task follows its usual course of escalating in detail and complexity. An example of the most recent project statement dealing with inherently safer process design is given in the appendix.

"Proceedings of the 2004 American Society for Engineering Education Annual Conference \& Exposition Copyright (C) 2004, American Society for Engineering Education” 
The project must allow students to emphasize the process of using a team format to meet the goals of the project. The level of difficulty of the project should be easily understood by the seniors and by many of the juniors. This creates the opportunity for these students to explain tasks and concepts to the less experienced students while retaining confidence that the tasks will be satisfactorily completed. Underclassmen will obviously be somewhat confused on how to go about solving the problem. A problem statement that significantly challenges the upper-level students in terms of technical skills or knowledge is not effective since having the needed skill set to reach the project goal is an established element in successful teams. Rather than learning new technical skills, we want them to put some time into planning the project timeline, organizing the activities, partnering and learning from each other, preparing for meetings, preparing memos, reports, and the presentation. From prior experience we know that making the problem challenging can force the upper level students to leave the underclassmen behind in order to focus on the final technical design. We often ask the teams to provide a recommendation to an imaginary supervisor where the recommendation relies not only on the final technical process design and associated economics but also on the detailed information gathered by the less-experienced team members. For example, in the most recent project freshman were typically responsible for interpreting federal regulations associated with process safety and environmental compliance. This is a second aspect of VITDP that creates positive interdependency, i.e. members perceive that they cannot succeed unless everyone succeeds, which is critical for cooperative learning. See the Cooperative Learning Center at the University of Minnesota (www.clcrc.com) for more information on this point.

The project statement should allow each level of student the opportunity to learn something they perceive as valuable. In this case the problem statement cannot be too basic or elementary. It is not sufficient to simply identify learning outcomes that faculty feel are important. Students will be more motivated to put the time and energy into the project if they perceive value in the activities. Finally, the problem must be doable in terms of the expected time needed to perform the tasks. Time management was the number one negative aspect of earlier attempts at the VITDP. We have a limited window in terms of keeping mentors available with minimal disruption to their schedules, minimizing the negative impact on the students' other academic responsibilities, and keeping the students' enthusiasm for the project high.

\section{Construction of the teams}

Following the advice of many educators who specialize in collaborative learning, the teams are arranged using specific criteria. Arranging the teams allows us to draw on knowledge gained from previous VITDP projects concerning technical abilities, interpersonal skills, behaviors, and attitudes for every student except the freshman. Given that collaboration, communication, and cooperation are key elements for success, our prior knowledge of individual behavior provides the potential to foster positive social interactions within each team. Based primarily on evaluations from previous VITDP experiences, each student is given an initial teamwork rating of 1) poor, defined as likely to drop out of participation, 2) fair, defined as willing to participate but work habits deemed unreliable to complete critical assignments, 3) good, defined as willing to collaborate with others and can complete tasks, or 4) excellent, defined as exceptional teamwork skills. In addition, each instructor is asked to submit an opinion based on the student's class performance to date.

"Proceedings of the 2004 American Society for Engineering Education Annual Conference \& Exposition Copyright (C) 2004, American Society for Engineering Education" 
The principles for arranging the teams are as follows:

- The number of teams is dictated by the size of the senior class.

- Teams that meet with industrial mentors must be able to meet at 5 PM. The number of teams with industrial mentors is dictated, therefore, by the class with the least number of students choosing this option. Usually half of the teams have an industrial mentor.

- Assign two seniors to every team such that one is capable of performing the highly technical tasks (i.e. process simulation, design calculations) while the other is capable of project organization and people skills. This combines two critical skills needed for project completion: technical and teamwork skills.

- Juniors are added to each team to obtain heterogeneity in both teamwork and technical skills (i.e. poor through excellent ratings).

- Sophomores are added to balance the teamwork ratings as well as gender and underrepresented groups (see next item).

- In order to minimize poor social interaction, no team has an isolated female or minority student member. Felder ${ }^{13}$ recommended this approach particularly for lower level students. In addition, we hope that informal networks develop for both women and minorities.

- Teams with mixed genders have at least one female junior or senior. This prevents women from being relegated to unimportant tasks in potentially gender-biased teams.

- At least one team consists of all women and one team of all men. This allows us the possibility to study gender differences in these team projects.

- As much as possible, freshman from the same section of Tools are assigned to the same team to allow for informal discussion and collaboration in completing their tasks.

- Using a short list of probable tasks developed from the problem statement, we check that each team has the needed personnel to complete the essential aspects of the project.

- Teams with the 'potentially' weakest seniors are assigned to the most effective mentors. If necessary, the mentor can impart some leadership to the team.

While the above may seem to be a fairly complicated strategy for team assembly, the extra level of complexity is important to minimize difficulties that can arise when teaming freshman through seniors.

\section{Findings}

Figure 1 displays the percent of freshman who agree (or disagree) with statements meant to identify their attitudes about engineering, teamwork, course projects and the role of the faculty. It is clear from Figure 1 that the freshmen are learning about both engineering and teamwork midway through the VITDP. Most of the freshmen have identified learning engineering skills as an important goal. Of particular note, however, is the fact that the freshmen have begun to recognize that realistic engineering problems are open-ended and that faculty are not the keepers of the one correct answer. Freshmen seem to adjust to the team based learning approach quickly. Mid-way through the project a significant fraction of the freshman are comfortable participating in technical discussions, are learning from their upper-class teammates and recognize that active participation in meetings is important for learning. As will be shown below, the percentage of freshmen who are comfortable in technical discussions increases significantly over the course of the VITDP. Their attitudes toward grading and personal goals indicate a moderate level of intellectual development as modeled by Kitchener and King ${ }^{14}$ but there is room for improvement.

"Proceedings of the 2004 American Society for Engineering Education Annual Conference \& Exposition Copyright (C) 2004, American Society for Engineering Education" 


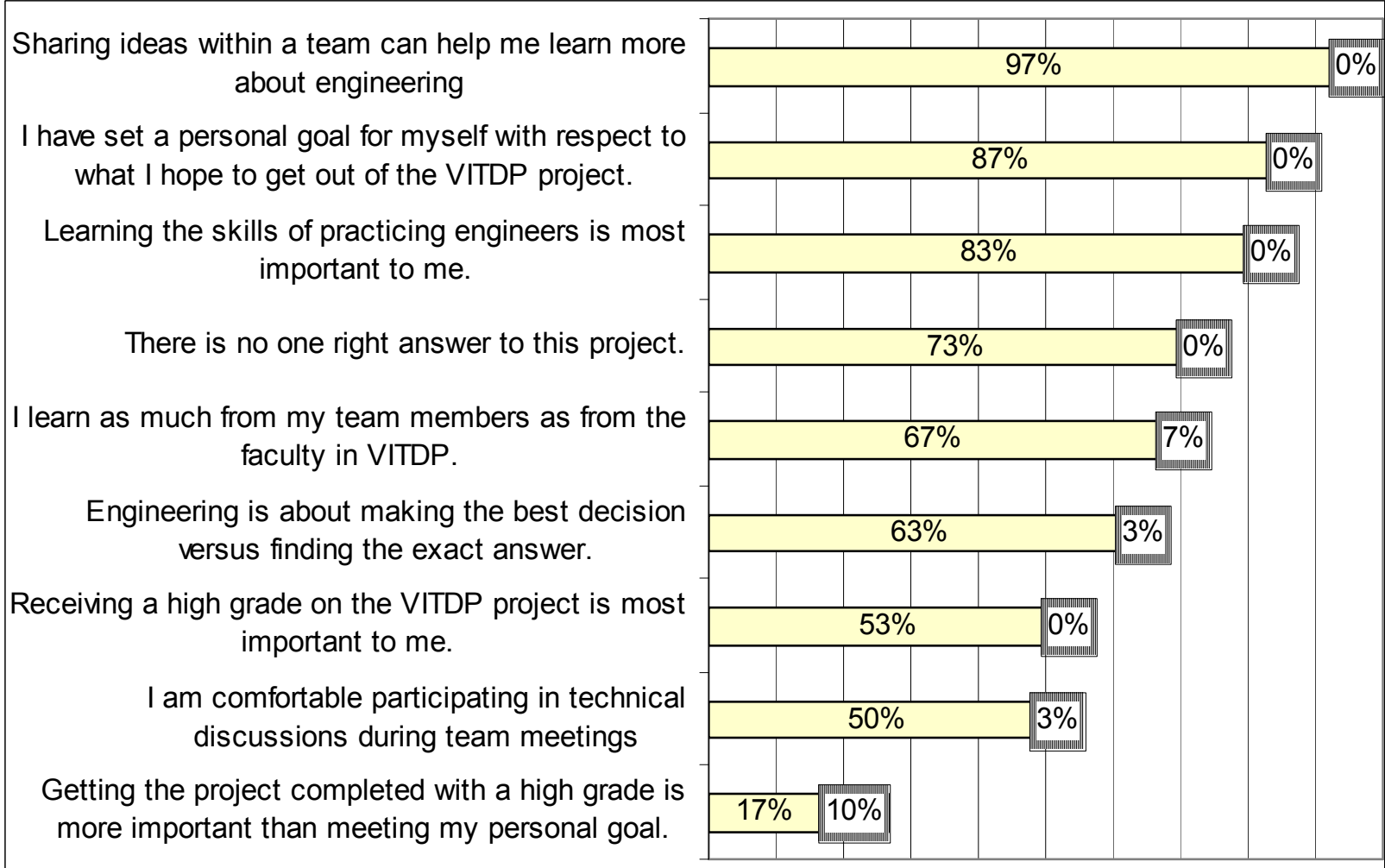

Figure 1. Percent of Freshman Who Agree (Disagree) With Mid-Project Survey Statements.

To perform a qualitative analysis of any change in safety content knowledge as a result of the VITDP, the rubric listed in Table 1 was developed. First, we present some key themes in the progression of the responses from one student followed by a content analysis from the freshman survey responses prior to the start of the project and then mid-way through the project.

Table 1. Safety Competency Scale

\begin{tabular}{|l|l|l|}
\hline Rating & \multicolumn{1}{|c|}{ Description } & \multicolumn{1}{|c|}{ Category } \\
\hline Intuitive & $\begin{array}{l}\text { Recognizes safety as an important issue, } \\
\text { lists generic personal safety elements but } \\
\text { not involving technical safety terms. } \\
\text { Example may be generic household safety. }\end{array}$ & Personal Safety \\
\hline Medium Personal level & $\begin{array}{l}\text { Recognizes common hazards (i.e. } \\
\text { flammable) and the need to protect against } \\
\text { them, example lab safety. }\end{array}$ & $\begin{array}{l}\text { Safety of } \\
\text { Others }\end{array}$ \\
\hline High Personal Level & $\begin{array}{l}\text { Listing of more technical aspects of } \\
\text { personal (i.e. reactivity, LEL, corrosive, } \\
\text { carcinogenic and individual safety issues. }\end{array}$ & $\begin{array}{l}\text { Safety of } \\
\text { Others }\end{array}$ \\
\hline Pre-Professional Level 1 & $\begin{array}{l}\text { Workplace safety related to regulations and } \\
\text { regulated safety practices. }\end{array}$ & Plant Safety \\
\hline Pre-Professional Level 2 & $\begin{array}{l}\text { Workplace safety related to plant } \\
\text { operations, unit operations, operating }\end{array}$ & $\begin{array}{l}\text { Safe Plant } \\
\text { Operations }\end{array}$ \\
\hline
\end{tabular}

"Proceedings of the 2004 American Society for Engineering Education Annual Conference \& Exposition Copyright (C) 2004, American Society for Engineering Education" 


\begin{tabular}{|l|l|l|}
\hline & conditions. & \\
\hline Pre-Professional Level 3 & Safety techniques such as HAZOP, what-if. & Design Safety \\
\hline
\end{tabular}

Students were asked to list safety related issues for a typical chemical plant on three separate occasions during the semester, 1) prior to the start of the VITDP project dealing with the safety analysis of a polyol chemical plant, 2) mid-way through the 6 week project, and 3) two weeks after the VITDP project students were asked to report on how they would analyze the safety issues for another chemical process. Claire is a de-identified freshman who wrote the following sequence of responses that we found to be typical responses.

Prior to the start of VITDP: Your safety -- must wear goggles, lab coat, so on; environmental safety; safety of others around you

Mid-way through VITDP: There are many things that can go wrong in a chemical manufacturing or process. There could be a leak or spill of a hazardous chemical. The temperature of some processing equipment could get too high resulting in an explosion. Any equipment could malfunction for some reason, such as if it isn't properly used or taken care of. Inexperienced or badly trained workers could cause a number of problems. If guidelines for handling and storing hazardous chemicals are not followed correctly, many problems could arise.

Two weeks after VITDP from an assigned safety analysis report: There are four main steps to a safety analysis. The first, called risk identification, includes the Process Hazard Analysis (PHA), which tries to identify possible problem areas in the design process so that injuries and other accidents can be avoided. These problems can be caught by using the PHA's Hazard Evaluation Techniques. Basically, they cover things such as a what-if scenario checklist, hazard and operability analysis, failure mode and effects analysis, fault tree analysis, and any combination of these methods/ equivalent alternate method. The next step is risk analysis, estimation, and judgment. A consequence analysis is included in this step. The third step is risk management systems. In this step, a process must undergo a PSM assessment, an accident prevention assessment, where the facility and personnel are evaluated. The fourth step is safety and risk compliance. This step determines whether a process and facility is within the OSHA and EPA regulations.

Clearly Claire's knowledge level prior to entering the chemical engineering program stems from personal safety specifically those elements related to chemical lab safety. Mid-way through the VITDP project (approximately 7 weeks into the semester) her team has now met on three occasions to discuss key safety elements in the polyol process and she can extemporaneously report on many elements related to plant safety, safe plant operations and implications from safety regulations. During the final stage, she has little difficulty reporting on the elements involved in the third pre-professional level related to safety design. At this stage, she would not claim to be capable of performing even a minimal safety design, but she has created an opportunity for future knowledge to be constructed from this VITDP experience.

During the project period we see a dramatic shift towards process related safety issues and relevant safety regulations as seen in the histograms in Figure 2. In the time allotted to list the

"Proceedings of the 2004 American Society for Engineering Education Annual Conference \& Exposition Copyright (C) 2004, American Society for Engineering Education" 
safety issues, students initially stressed personal and/or lab safety. After three weeks into the VITDP project, these same students opted to not include more simplistic categories such as personal safety, fire, and even typical PPE lab safety elements. The freshmen are equating safety and environmental issues more strongly after three weeks into the project, particularly noting the hazardous nature of the chemicals. This is most likely due to the type of information gathering many teams assigned to the freshman members. Prior to the start of the project, only one student listed an element related to process operations as dealing with safety. After three weeks of project conversations with their teams, approximately $80 \%$ of the freshman are equating safety with process and plant operations Some of the process related issues that students list are quite advanced including exothermic reactions, advanced process control schemes, etc.

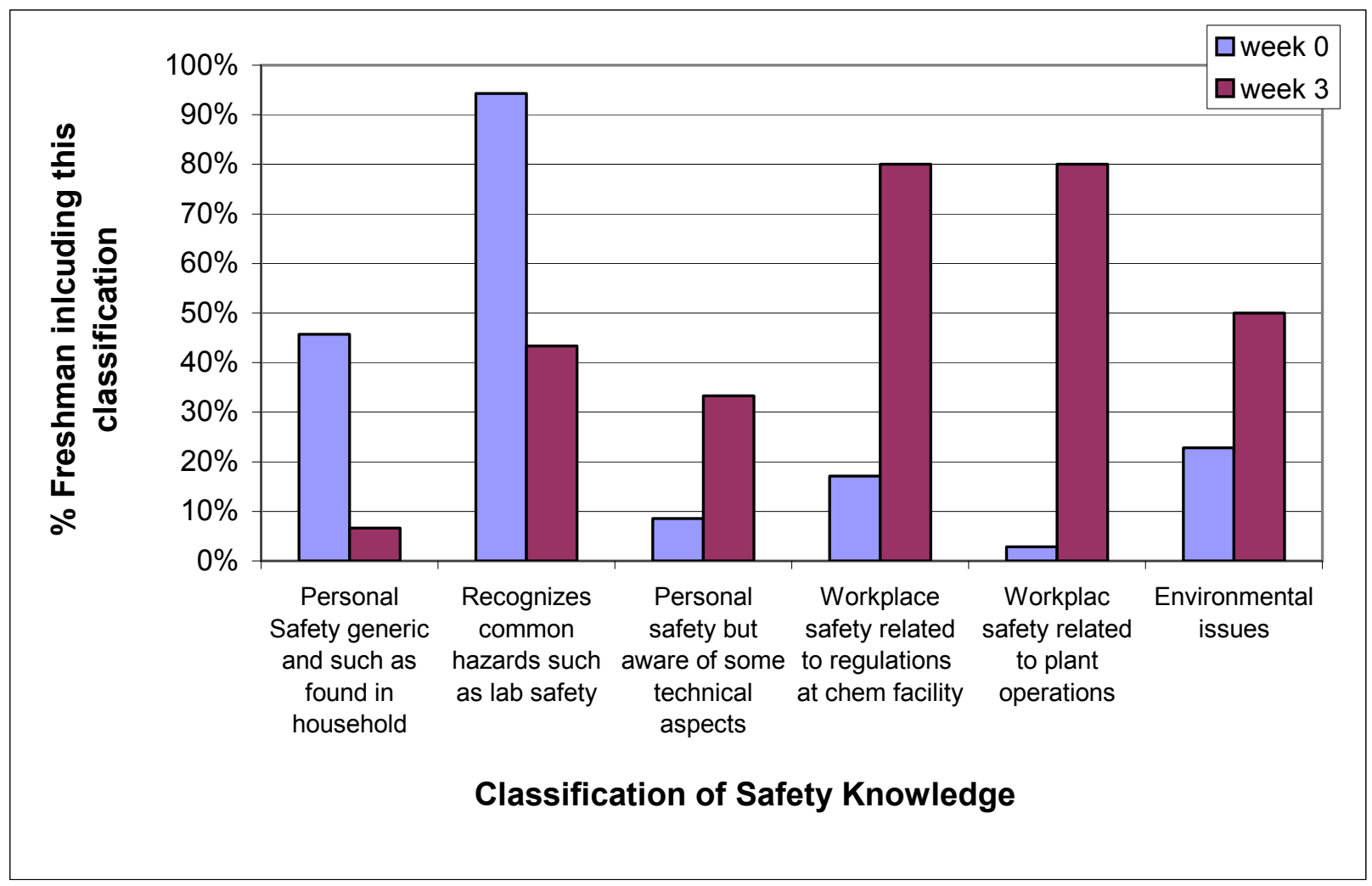

Figure 2. Change in process safety related content knowledge during VITDP project period.

How the freshmen are learning is another important element in the VITDP instructional environment. We performed a content analysis from two reflective journals all students were asked to submit during the latter weeks of the semester and after the completion of the VITDP project. The journal prompts were:

(a) Describe how this VITDP project has made you: 1) consider the definition of safety, 2) think about safety analysis, and 3) consider how safety aspects can be applied in ChemE design.

(b) How did safety considerations influence or cause your team to consider changes or additions to the process design?

(c) Which safety aspects of the project were the most familiar to you? Why?

(d) Which safety aspects of the project were the least familiar to you? Why

"Proceedings of the 2004 American Society for Engineering Education Annual Conference \& Exposition Copyright (C) 2004, American Society for Engineering Education" 
We categorized the freshmen's responses based on four elements from the NRC report, How People Learn ${ }^{6}$ and the results of the content analysis are shown in Figure 3.

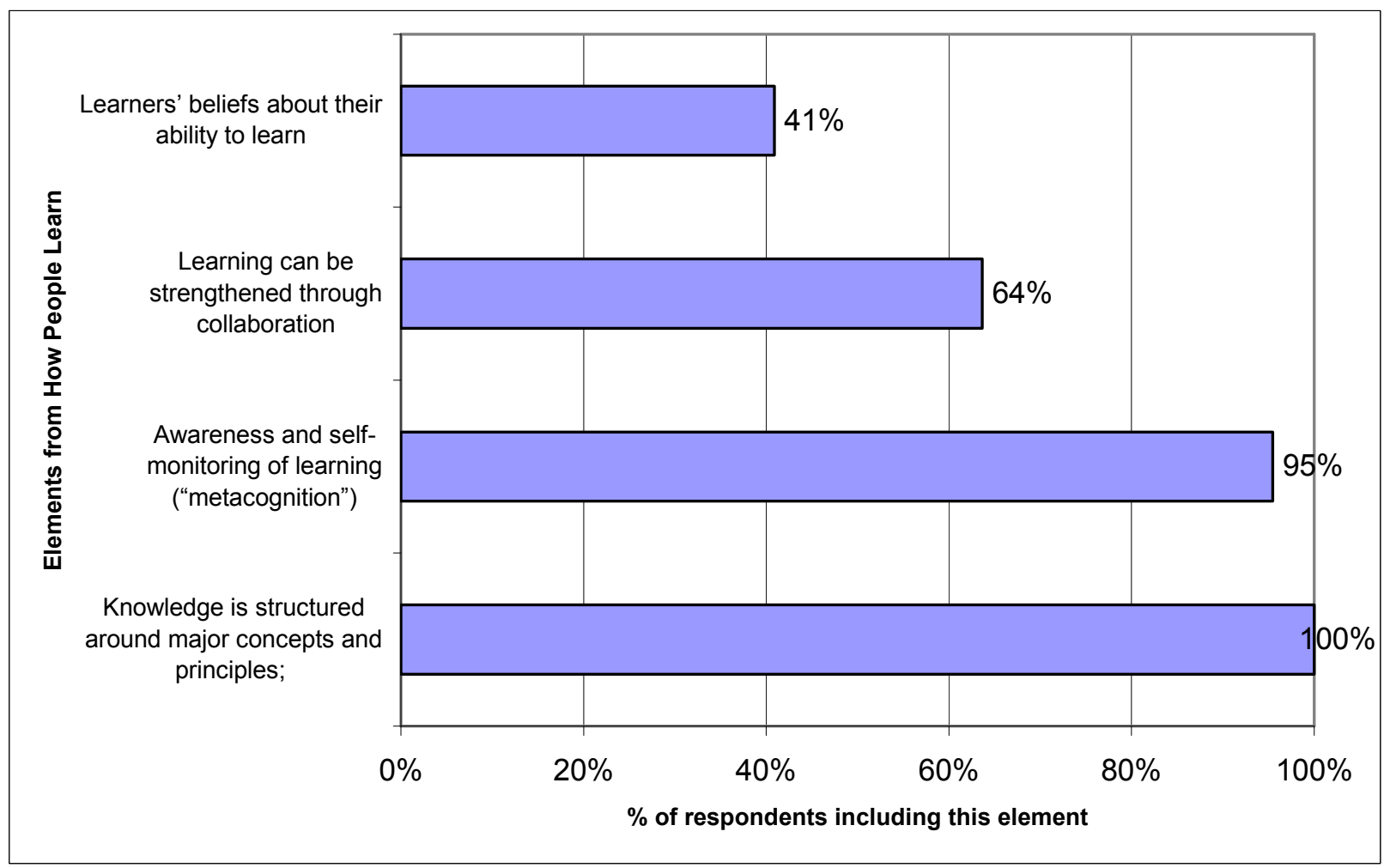

Figure 3. Freshmen Reflections on How They Learned.

We find it significant that even though the journal prompts are not directed towards how the student learned, many freshmen note these connections in their reflections. De-identified examples of specific comments related to each of the elements are as follows:

Learners' beliefs about their ability to learn: It has made my mind to be trained to think about safety first when doing anything like this.

Learning can be strengthened through collaboration: The least familiar safety aspects were the technical details, such as mixing ratios, storage, etc. You have to hear about these ones from someone with experience to actually realize them.

Awareness and self-monitoring of learning ("metacognition"): This project has definitely redefined my definition of safety. I always just thought of safety as being cautious in your actions when dealing with chemicals, but there is a lot more to it than just that.

Knowledge is structured around major concepts and principles: This is where a lot of monitoring equipment comes into play and by monitoring the temperature and amount of chemicals within a reactor or some other kind of equipment, we can prevent accidents.

\section{Project evaluation results}

At the end of the semester, the students were asked to complete a 54 question project evaluation survey and report on what they learned from the project as well as how VITDP could be

"Proceedings of the 2004 American Society for Engineering Education Annual Conference \& Exposition Copyright (C) 2004, American Society for Engineering Education" 
improved. The following provides some analysis from the survey results although a complete statistical analysis is not provided at this time.

Written comments on 1) the most important thing they learned and 2) what they most liked about VITDP from the freshman students were classified into distinct categories as shown in the two pie charts in Figure 4. Freshman learn at a very early stage in their academic career that teaming is important for success as an engineer. PIECHART A shows that $45 \%$ of the freshmen have identified teaming as the most important skill learned through VITDP. This result is not a surprise because of the emphasis the instructors and society puts on teamwork. However, note that the freshman have listed communication as the second most important skill, ranking it above design tasks and a general overview of chemical engineering. PIECHART B clearly demonstrates that the freshmen enjoy the team-based learning. $85 \%$ percent of the freshman declared that some aspect of teaming was the part of the VITDP that they liked the most. Retention of students relies heavily on their attitude about the program and how they are learning. While we have not performed a detailed analysis of retention as it relates to VITDP, preliminary results suggest that our freshman retention percentage is unchanged but there is an increase in retention for both sophomores and juniors. Anecdotes suggest that some freshman quickly learn that chemical engineering is more difficult than they expected and those students transfer to another major.

Figure 5 shows the distribution for all class levels of the most important elements learned during the most recent VITDP project. Written comments from the end of the VITDP project survey were sorted into the same five categories as shown in the figure. With the exception of the junior students, each class felt they enhanced their teamwork abilities more than any other skill category. The second most important element for the freshman was learning about chemical engineering and what chemical engineers actually do. In addition, $12 \%$ of the freshman noted that they learned that freshman can really do engineering at this early stage in their academic program. Sophomores, who are participating on their second VITDP project, also reported enhancing engineering skills. The third-year students have a more evenly distributed assessment of what they learned. They see a gain in their technical knowledge (i.e. design, safety, and other ChE skills) most likely because they are at a stage where they can be more actively involved in the technical aspects of the project including aspects not yet covered in their core courses. Interestingly, senior students who have now participated for the fourth time in VITDP, see the largest gain in their teamwork abilities. This is likely to stem from their role as team leader where they have to be the key player in determining the project plan and by providing more complete explanations of the 'big-picture' to the freshman. As expected they did not see an enhancement to their ChE skills, but rather a significant increase in their knowledge of process safety and safety analysis.

The results from Figure 5 suggest that the vertically integrated instructional framework creates the opportunity for deep learning in that each level of student is enhancing their professional skills. Thus, upper-level students do not see VITDP as a course where they must 'put up with' inexperienced freshman students although they do feel that they carry more of the workload for the project. The team creates the opportunity for significant social learning to be constructed each time the students participate. Some typical responses to 'What was the most important thing you learned from VITDP this year?' include the following:

"Proceedings of the 2004 American Society for Engineering Education Annual Conference \& Exposition Copyright (C) 2004, American Society for Engineering Education" 
Freshman: Everything involved in the process of chemical engineering design, how to present an effective presentation, how to work as a team and an individual at the same time, and a better idea of what being a chemical engineer involves.

Sophomore: I learned that just because I wasn't taught something in the classroom it doesn't stop me from getting the job completed with help from others.

Junior: Each year I take part in the project, I see it from a different perspective. This year, now that I have progressed further in my major, I got a better understanding of the overall structure of the project (i.e. knowing we need background info, safety, econ, process design, of these, I learned the most about safety.

Senior: As long as I gave specific instructions to my other team members on what they needed to accomplish the assigned tasks would get done. If I did not give my team step-by-step instructions little would get accomplished. I learned I can be a good team leader. This class required more time than some 3 credit courses.

"Proceedings of the 2004 American Society for Engineering Education Annual Conference \& Exposition Copyright (C) 2004, American Society for Engineering Education" 


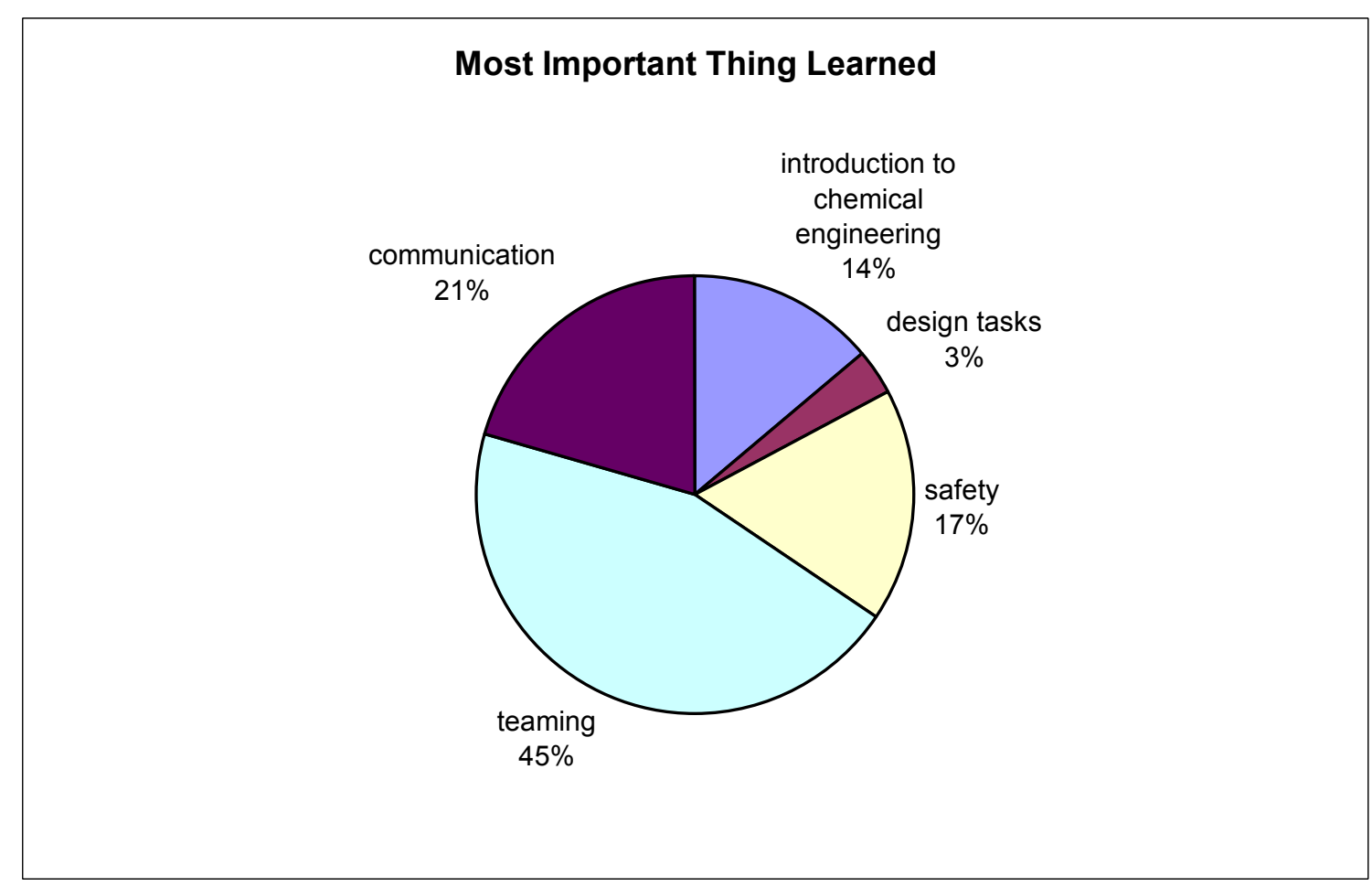

PIECHART A. Freshmen responses to project evaluation survey.

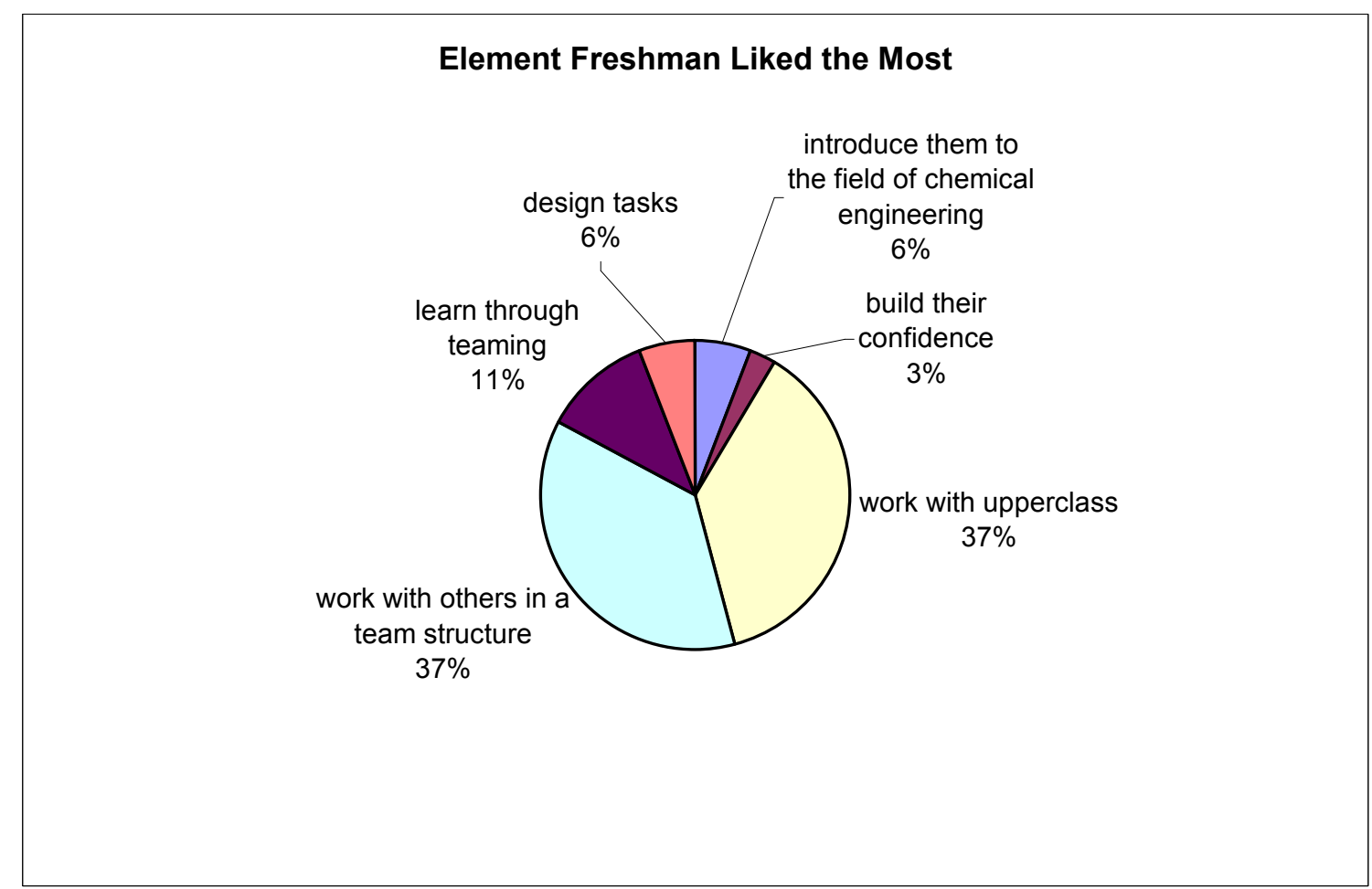

PIECHART B

Figure 4. Classification of Freshman Comments from Course Evaluation Survey

"Proceedings of the 2004 American Society for Engineering Education Annual Conference \& Exposition Copyright (C) 2004, American Society for Engineering Education" 


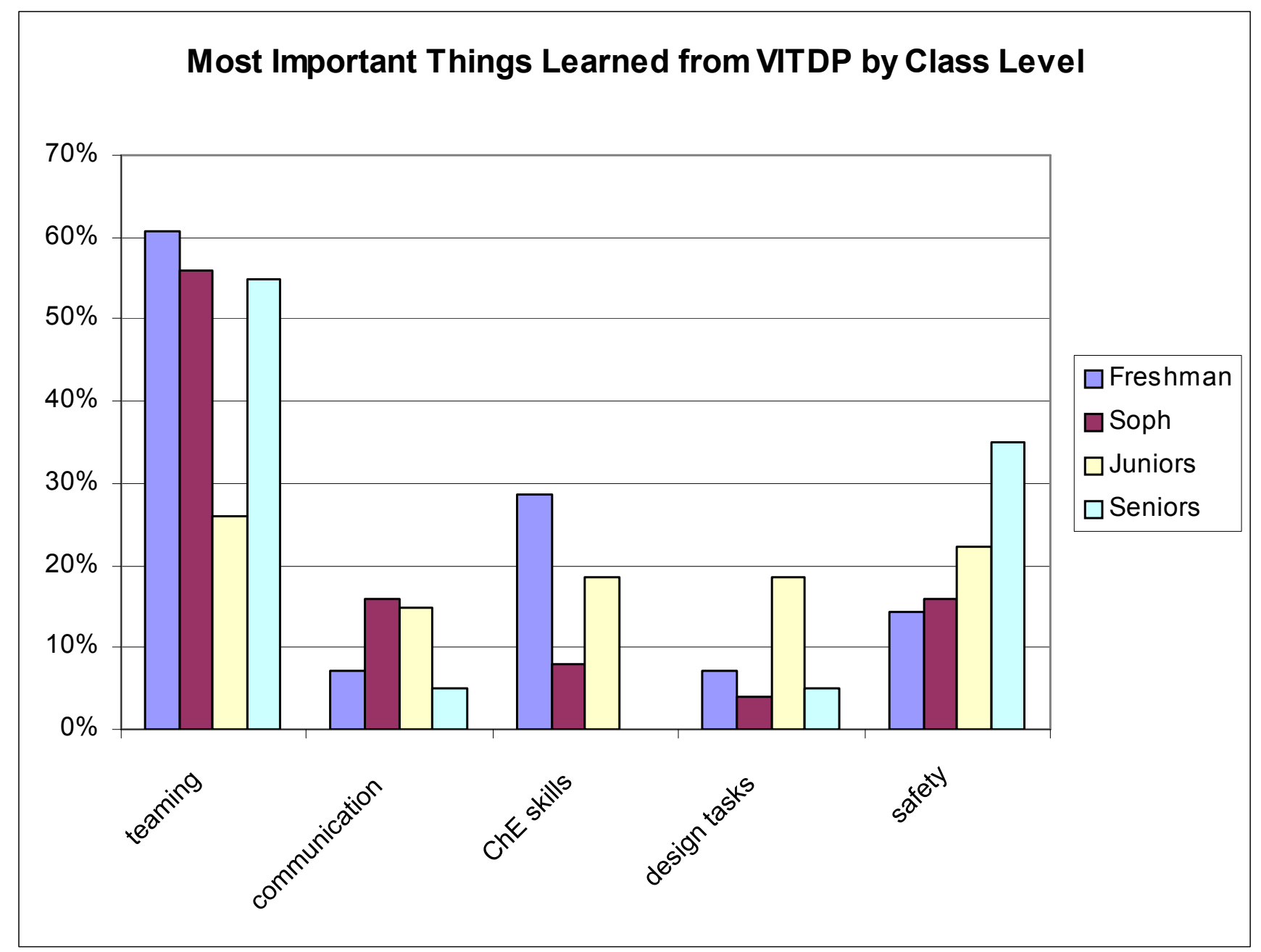

Figure 5. Distribution of Self-Reported Learning by Class Level.

"Proceedings of the 2004 American Society for Engineering Education Annual Conference \& Exposition Copyright (C) 2004, American Society for Engineering Education" 


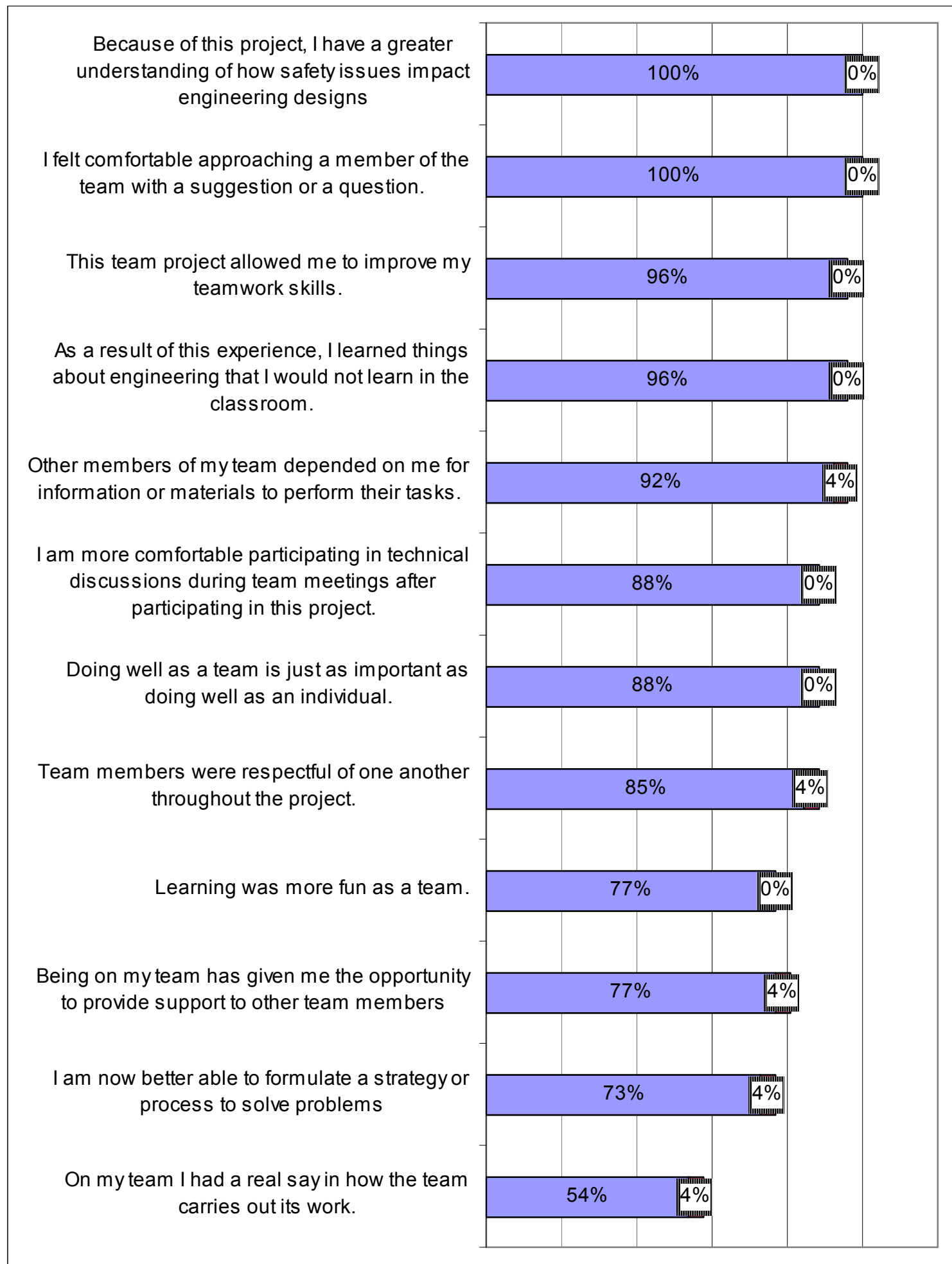

Figure 6. Percent of Freshman Who Agree (Disagree) with Selected End of Semester VITDP Project Evaluation Statements.

"Proceedings of the 2004 American Society for Engineering Education Annual Conference \& Exposition Copyright (C) 2004, American Society for Engineering Education" 
Figure 6 shows that the majority of the teams created the positive interdependence within their teams that is necessary for effective team based learning. For example, a strong majority of the freshman felt respected and responsible. $100 \%$ of the freshman felt comfortable in asking questions of their upperclassmen; in terms of creating an intradepartmental student network, this is exactly the type of result we would like to see. As a result of the interdependence freshman increased their technical confidence. Well over $80 \%$ of the freshmen were very comfortable with team discussions and taking on responsibility at the conclusion of the VITDP. Students learn best from one another and the VITDP provides a mechanism for breaking down the barriers to communication between classes.

Comparisons of the results from Figure 6 show that similar themes are apparent across all levels as shown in Figure 7. The vast majority of the students feel that that VITDP presents an active, collaborative framework for learning. All levels are actively engaged with each other as evident from the result that $70 \%$ of the seniors report they relied on other students to complete their project tasks. The vast majority of students report that they learned things they would not learn in the classroom. It should also be noted that the upper level students enjoy the time spent on the team project less than the other levels, particularly less than the freshman, but this is likely to be a result of the extra burden of responsibility which naturally falls on the most senior team members.

\section{Conclusion}

The vertically integrated team structure for our design project has shown to be an effective instructional framework for learning. Freshman experience many of the well-supported generalizations from the research literature on what matters most in student success. The VITDP project statement builds on prior knowledge of the freshman even though they believe they have no prior knowledge. Freshman build connections with other students from all levels within the program, in addition they build connections with technical skills and professional skills via the design project. Collaboration as a mode of learning is effective and the students report considerable enhancement in their content knowledge as a result of working in their teams. Actively engaging with others on the project has been shown to be an effective way for students to construct new knowledge in a social context.

"Proceedings of the 2004 American Society for Engineering Education Annual Conference \& Exposition Copyright (C) 2004, American Society for Engineering Education" 


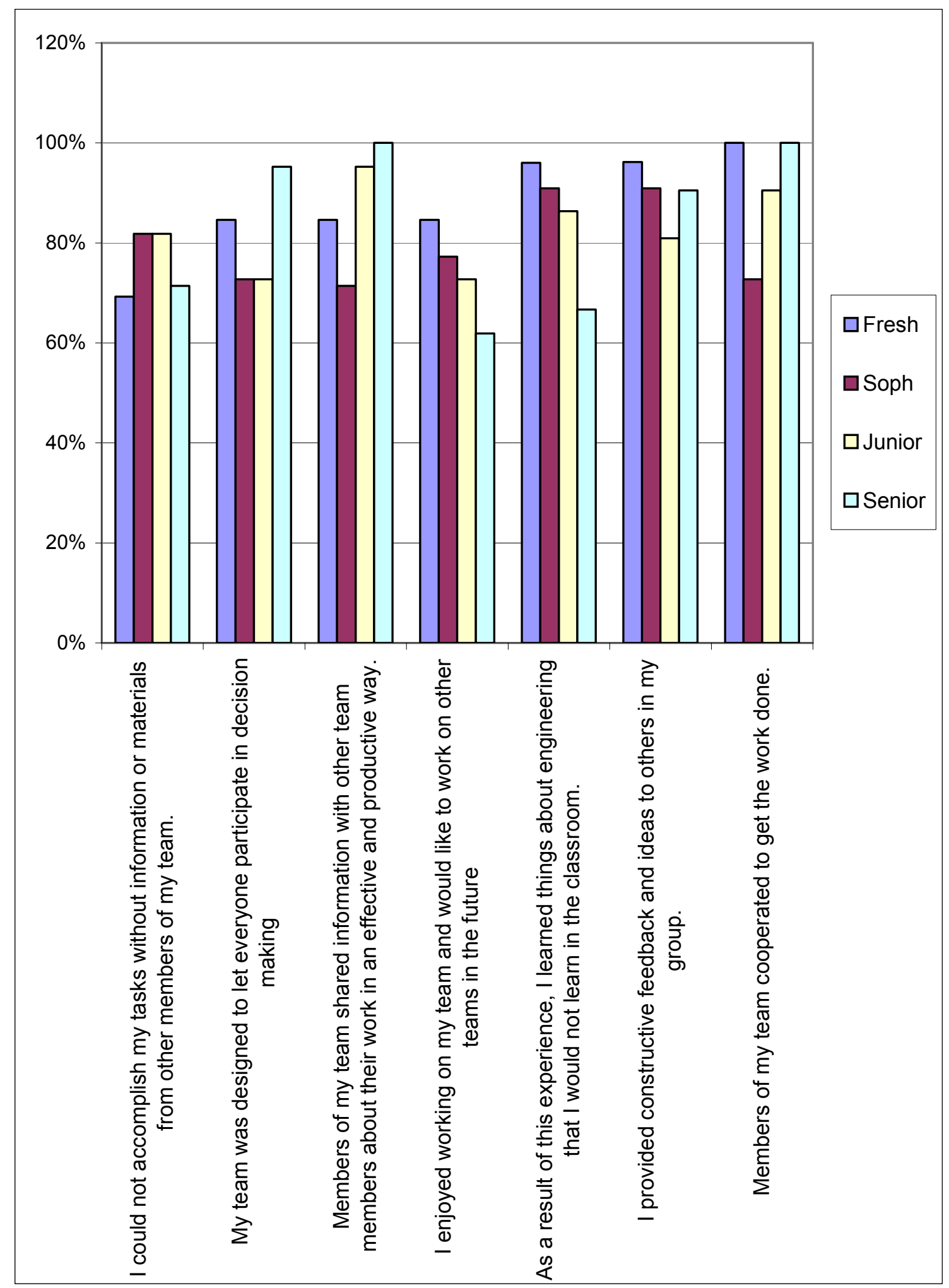

Figure 7. Comparison of Student's Attitudes Towards Elements Stemming from Multi-Level Vertical Integrated Structure.

"Proceedings of the 2004 American Society for Engineering Education Annual Conference \& Exposition Copyright (C) 2004, American Society for Engineering Education” 


\section{Acknowledgements}

We are indebted to the faculty in the Department of Chemical Engineering for their dedicated support and implementation of the VITDP. We are also grateful for the input and assistance by our industrial colleagues, particularly the outstanding service they provide as team mentors. Finally, we must acknowledge that without the hard work and thoughtful critique of our efforts by our students over the past several years, none of this would have been possible. This work was partially funded through National Science Foundation grants EEC-0230659 and EEC0230649 .

\section{References}

[1] MIT, Frontiers in Curriculum Reform. Downloaded from http://mit.edu/che-curriculum. (2003).

[2] Tufts, Curriculum Development Workshops on the Integration of Chemical \& Biological Engineering. Downloaded from http://ase.tufts.edu/chemical. (2004)

[3] Smith, K., 1996. "Cooperative Learning: Making 'Groupwork' Work," in Using Active Learning in College Classes: A Range of Options for Faculty, New Directions for Teaching and Learning, no. 67, ed. Tracey Sutherland and Charles C. Bonwell (San Francisco: Jossey-Bass), 71-82.

[4] Yokomoto, C. F., M. Rizkalla, C. O’Laughlin, M. El-Sharkawy, and N. Lamm, 1999. “Developing a Motivational Freshman Course in Using the Principle of Attached Learning”, Jour. Eng. Ed., 88, 99.

[5] Lave, J. and E. Wenger, 1991. Situated Learning: Legitimate Peripheral Participation, Cambridge University Press.

[6] National Research Council (2000). How people learn : Brain, mind, experience, and school. Washington, D. C.: National Academy Press.

[7] Blake, R. W., \& Blake, R. W. (2000). Science as a way of knowing: Using reader response as a means to construct a personal understanding of science literature. In Rubba, P. A., Rye, J. A., Keig, P. F., Di Biase, W. J., (Eds.). Proceedings of the Annual Meeting of the Association for the Education of Teachers in Science (Akron, OH, January 6-9, 2000). p. 831 - 844. ERIC Number: ED438191.

[8] von Glaserfeld, E. (1995). Radical constructivism: A way of knowing and learning. Washington, D. C.: The Falmer Press, p. 1.

[9] Atwater, M. M. (1996). Social constructivism: Infusion into the multicultural science education research agenda. Journal of Research in Science Teaching, 33(8), p. 821-837.

[10] Blanck, G. (1990). Vygotsky: The man and his cause. In Moll, L. C. (Ed.) Vygotsky and education: Instructional implications and applications of sociohistorical psychology. Cambridge: University of Cambridge Press, p. 44.

[11] Reynolds, B., 1965. Learning and Teaching in the Practice of Social Work, Russell and Russell, New York.

[12] Seat, E. and S. Lord, 1999. "Enabling Effective Engineering Teams: A Program for Teaching Effective Interaction Skills", Jour. Eng. Ed., 88, 385.

[13] Felder, R. and R. Brent, 2001. "Effective Strategies for Cooperative Learning", J of Cooperation \& Collaboration in College Teaching, 10, 69-75.

"Proceedings of the 2004 American Society for Engineering Education Annual Conference \& Exposition Copyright (C) 2004, American Society for Engineering Education” 
[14] King, PM and KS Kitchener, Developing Reflective Judgment, Jossey-Bass Publishers, San Francisco, 1994.

\section{Biographical Information}

FRANCIS BROADWAY received a Ph.D. in elementary education, which he earned in 1997 from the University of South Carolina. He holds an undergraduate degree in chemistry and worked as a middle and secondary school instructor before attaining his Ph.D. He is very active in the research on and evaluation of pre- and in-service teacher education programs. Prof. Broadway also plays a major role in cross-college collaborations involving the colleges of Education, Engineering, and Arts \& Sciences. His research interests involve assessment of student cognitive learning and performance and the interface of language arts literacy and science literacy.

H. MICHAEL CHEUNG is a Professor in the Department of Chemical Engineering. He earned his B.S. in 1979, his M.S. in 1982, and his Ph.D. in 1985, all at Case Western Reserve University in Cleveland, Ohio and is a registered professional engineer (Ohio). He joined the chemical engineering faculty at The University of Akron in the Fall of 1984 as an assistant professor, was tenured and promoted to associate professor in 1989, and became full professor in 1998. His research areas include supercritical fluids processing, nanostructured materials synthesis, ultrasound driven processes, and laser measurement methods.

EDWARD EVANS earned his Ph.D. in 1998 from Case Western Reserve University and has been teaching Chemical Reaction Engineering and Materials Science for the last five years in the Department of Chemical Engineering at The University of Akron. He has included material from the National Effective Teaching Institute Workshop (6/17/99-6/19/99) in many of these courses. Dr. Evans is currently funded under an NSF Bridges for Engineering Education (BEE) grant and a Department Level Curriculum Reform (DLCR) grant to implement novel approaches to engineering education. Dr. Evans participates in a multidisciplinary research group that studies vapor deposition of nanostructured materials.

HELEN QAMMAR is an Associate Professor in the Department of Chemical Engineering. She earned her PhD in chemical engineering at the University of Virginia in 1986 and worked as a research fellow at Resources for the Future prior to joining the University of Akron. She is actively involved on campus in the scholarship of teaching and learning including chairing the college ABET committee. Research interests include the application of nonlinear dynamics to process identification and control.

REX RAMSIER earned his Ph.D. in physics from the University of Pittsburgh in 1994 and after two years in industry joined the faculty at The University of Akron. He is currently an Associate Professor with joint appointments in several departments. He is active in promoting student success, and has received the campus-wide outstanding teacher award as well as many other teaching related honors. His research interests include functionalized materials and surface coatings, nanofibers and nanolithography, and surface science.

SANDRA SPICKARD PRETTYMAN is an Assistant Professor in the Department of Educational Foundations and Leadership. She earned her Ph.D. in Theory and Social Foundations from The University of Toledo and taught secondary English and French prior to pursuing her Ph.D. Her research interests include the relationship between gender and education and the use of qualitative research methods and analysis. Current research focuses on gender issues in engineering and the use of different pedagogical approaches to promote learning and student development.

"Proceedings of the 2004 American Society for Engineering Education Annual Conference \& Exposition Copyright (C) 2004, American Society for Engineering Education" 


\section{Appendix:}

\section{VITDP Project Statement for Fall 2003}

Your team is in charge of the preliminary process design for a new polyols manufacturing plant to be built as an expansion of our Portsmouth, Ohio facility. Our corporation also is considering investing very heavily in polyols, well beyond the scope of the current project, and is looking for new ideas to improve the economics and safety of future polyol processes. We plan to build a conventional polyols process in Ohio along the Ohio River at our Portsmouth facility to meet demand in the Ohio Valley. Your team is to present a preliminary design using conventional polyols processing technology. We may need to license from BASF in particular their Pluracol product line technology. Along with creating a preliminary design, your team is to identify key safety issues for follow up during detailed design. Detailed design will likely be handled by outside contractors, but we need internal expertise from the preliminary design to effectively manage that effort.

I want to emphasize the need for careful consideration of safety issues. This technology is new to our corporation and we want to be absolutely certain that we've identified all of the significant safety concerns for protection of our personnel, our investment, and, most importantly, the safety of those in the nearby community. In addition we're, of course, also interested in making sure that we comply with applicable federal, state, and local regulations. For the preliminary design phase we can focus on our obligations under federal statutes. It is essential that we develop plans and background materials for all of the formal safety reviews that will come as part of the detailed design even though we will not be doing those formal reviews as part of this phase of the project. Some of the items that come to mind are potential compliance issues with CFR 1910 sections 38 \& 119, RCRA (Resource Conservation and Recovery Act), CAA (Clean Air Act), SARA, and CWA (Clean Water Act). Also, a historical issue you may want to look into is the catastrophic loss of a BASF polyols plant, I believe in 1975 in Geismar, LA.

Key design targets for the new plant:

- Total operating time: $8000 \mathrm{hr} /$ year and allowed wash/cleanout time: $160 \mathrm{hr} / \mathrm{year}$

- Total production capacity: 120 to 125 million $\mathrm{lb} / \mathrm{year}$

- Four main products of varying EO/PO content

○ "A" $60 \%$ of capacity $(\sim 72 \mathrm{MM} \mathrm{lb/y);} \mathrm{10} \mathrm{hr} \mathrm{net} \mathrm{cycle} \mathrm{time}$

○ "B" $20 \%$ of capacity $(\sim 25 \mathrm{MM} \mathrm{lb} / \mathrm{y}) ; \sim 10 \mathrm{hr}$ net cycle time

○ "C" $10 \%$ of capacity $(\sim 13 \mathrm{MM} \mathrm{lb} / \mathrm{y}) ; \sim 11 \mathrm{hr}$ net cycle time

○ "D" $10 \%$ of capacity $(\sim 13 \mathrm{MM} \mathrm{lb} / \mathrm{y}) ; \sim 14.5 \mathrm{hr}$ net cycle time

Long term we hope to leapfrog present technology and move to an inherently safe process for polyols manufacture. We believe that doing so will position our company to absorb most of the projected polyols market growth ourselves and possibly to displace weaker suppliers. Your team is to propose opportunities for process research and development efforts for an inherently safe polyols process.

Our timeline is to have this phase of the project completed by the first week in November. Please forward to me at your earliest convenience, but not later than COB next Friday, 9/26, your draft project charter and workplan. Please anticipate submitting weekly progress reports and workplan updates.

"Proceedings of the 2004 American Society for Engineering Education Annual Conference \& Exposition Copyright (C) 2004, American Society for Engineering Education" 